\title{
Environmental Impact Assessment of the Tidal Link Failure and Sea Intrusion on Ramsar Site No. 1069
}

\author{
Ali Asghar Mahessar \\ Sindh Barrages Improvement Project \\ Irrigation Department, Government of Sindh \\ Sindh, Pakistan \\ amahessar@yahoo.com \\ Sumeera Qureshi \\ Department of Analytical Chemistry, \\ University of Sindh, \\ Jamshoro, Pakistan \\ s.dr582@gmail.com \\ Abdul Latif Qureshi \\ US-Pakistan Centers for Advanced Studies, \\ Mehran University Engineering \& Technology, \\ Jamshoro, Sindh, Pakistan \\ latif.qureshi@faculty.muet.edu.pk
}

\author{
Abdul Nasir Laghari \\ Department of Energy and Environment, \\ Quaid-e-Awam University of Engineering, Science and \\ Technology, Nawabshah, Pakistan \\ a.n.laghari@quest.edu.pk \\ Insaf Ali Siming \\ Department of Basic Sciences and Related Studies, \\ Quaid-e-Awam University of Engineering, Science and \\ Technology, Nawabshah, Pakistan \\ insaf.siming@quest.edu.pk \\ Faheem Akhtar Shaikh \\ Department of Chemical Engineering, \\ Quaid-e-Awam University of Engineering, Science and \\ Technology, Nawabshah, Pakistan \\ faheemakhtar86@yahoo.com
}

\begin{abstract}
This paper presents the impact on the RAMSAR site No. 1069 that receives fresh water by the Kotri drainage system. At present, the complex faces threats by effluents from the Left Bank Outfall Drain (LBOD) system and from saline seawater intrusion during high tides. These threats have destroyed the ecosystem of the lakes Cholari, Mehro, Pateji and Sanhro belonging to the complex. The total present lake area, maintained at the Cholari weir crest level, is about $170 \mathrm{~km}^{2}$. The lakes are expanding, available data shows that there is an increase up to $700 \%$ in the original lakes' area, from 6058 to 41220 acres from 1954 to 1977 . This is mainly caused by the operation of Kotri Barrage surface drainage system and has positive impact on lakes' ecology because the drainage effluent is of marginal salinity. The rapid increase in the lakes' area, of about $40 \%$ within 2 years after the functioning of the Tidal Link with saline effluents from LBOD and sea intruded water have changed the ecology of the area. This posed significant impact on the ecosystem. Conversely, a similar rise in water level due to sea intrusion has nearly doubled the surface area and reposed a negative impact on the system. These lakes were giving shelter to a wide variety of local and migratory birds and had aquatic biodiversity. Hence, parts of Sanhro and Mehro dhands have been recognized by the RAMSAR Convention.
\end{abstract}

Keywords-Tidal Link; Sanhro and Mehro dhands; LBOD; ecosystem; sea intrusion

\section{INTRODUCTION}

Tidal Link is the component which makes the LBOD unique among drainage projects in Pakistan and probably in the world. The saline water must be disposed of in such a way that it could not damage other areas or fresh water bodies. With the ever-growing awareness of the need to protect the natural environment, disposal to lakes, rivers or natural depressions has become unacceptable. The Tidal Link allows strongly saline effluents to flow directly to the sea. It extends from the end of the Kadhan Pateji Outfall Drain (KPOD) to the Sir Tidal Creek [1]. Prior to the construction of the Tidal link the water of Pateji/Cholri Dhand area was maintained at a level of approximately 5 feet above mean sea level by a natural land bar separating it from the Rann of Kutch. Since the construction of the Kotri surface drainage system in the 1960s, the Dhands have become an environmentally important wildlife sanctuary, and also support a thriving fishing industry [2].The spinal drain was constructed to dispose drainage water into sea via the Tidal Link [3]. The southerly section of the LBOD system was constructed in 1995 having length of 25 miles. It has a point of junction from KPOD to its outfall in Sir Creek [4].

Disasters that commonly occur in fast succession are cyclones, heavy rainfall, floods and droughts. Manmade disasters have affected the coastal population badly as well [5]. However, in several parts of Badin district, saline water has brought land degradation and submergence of the area due to failure of the system to meet the desired results. Coastal wetlands are of pivotal importance to human activities and natural systems $[6,7]$. However, it is challenging to determine quantitative measure values for the wetlands due to several factors such as complicated hydro-biological functions, 
socioeconomic context and diversity [8]. Policy suggests that both market and non-market values of the wetlands can be considered into account during decision making. Globally, 50\% reduction has been seen in the wetlands [9]. One third of the species are dependent on wetlands [10]. The urbanization and climate change are bringing about the wetlands at the brink of degradation [11, 12]. Sinatry and Shakoor Dhands lie at the Pakistan-India border and are fed by Dhoro Puran. The area is swampy at the location of Tidal Link and is covered with large interconnected water bodies such as Cholri, Pateji SanhroMehro, and Khadi Dhands [13]. After the construction of the LBOD, the natural flow of the water was altered and the waters from the 3 dhands flow into the Cholri and Cholri Weir via Shah Samando creek and Runn of Kutch into the open sea [14]. It is worth mentioning that more than two dozen breaches have taken place in the Tidal Link Drain after the Cyclone 2A. The Cholri Weir controlling the water level in dhands was damaged and completely washed out during the cyclone. This altered water flows and water exchange and affected the water emancipations from the LBOD in the area [14]. A sharp incline angle of the bank of the Tidal Link Drain near RD-93 was observed due to the impact of the Cyclone $2 \mathrm{~A}$ at various locations. The water from the Arabian Sea and from the Indian Territory now directly enters into the Tidal Link Drain. The movement of the water is unrestricted from the Tidal Link Drain to adjacent dhands and vice versa [15]. When the water salinity was tested at different RDs, high values were recorded at RD-114, RD-124, RD-93 and RD-74, indicating sea water presence. There has been a free exchange of water between Dhands due to the washing away of Tidal Link Drain at different places [15]. The high amount of salinity of the Rann of Kutch affects the salinity of Tidal Link Canal left bank as it flows through its breaches. At least up to 1997, the salinity conditions stayed favorable in Dhands. Presently, the range of salinity conditions goes from those typical for sea water to the hyper saline Pateji Dhand.

\section{STUDY AREA}

The drainage water across Pateji Dhand and Cholri into the Arabian Sea via Shah Samando Creek is delivered by the man made Tidal Link drain. The research study area is located at latitude of $24^{\circ} 29^{\prime} 7162^{\prime \prime} \mathrm{N}$ and longitude $68^{\circ} 60^{\prime} 5430^{\prime \prime} \mathrm{E}$. The length of Tidal Link is $41 \mathrm{~km}$ starting from its juncture point with KPOD in the Northeast upto the Shah Samando Creek in the Southwest. The Tidal Link is built in such a way that it can transport about 3,118 cusecs of drainage water. The alignment of the tidal Link passes across Pateji and Cholri Dhands which are linked with Mehro and Sanhro Dhands. These Dhands have drained the excess water into the Rann of Kutch. Tidal Link now blocks this drainage.

\section{MATERIALS AND METHODS}

The $\mathrm{pH}$ and salinity values of Tidal Link and Dandhs were measured on site.

\section{A. $p H$ Meter}

The HI 8014 measures $\mathrm{pH}$ with temperature compensation. It measures QRP as well. Different modes of measurements can be switched by the user.

\section{B. Refrectometer}

The salinity and specific gravity of sea water can be measured using this device.

\section{Failure of Constructed Cholri Weir}

The design of the weir was in such a way that it could flow in either direction to the tidal cycle having a cresl level of $4.5 \mathrm{ft}$ and length of $18000 \mathrm{ft}$. The water level in the Dhands must not exceed the limit of $6 \mathrm{ft}$. As a comparison, the designed water levels in the incoming Karo Ghungro and FuleliGuni outfall drains are 10 and $11 \mathrm{ft} \mathrm{[16].}$

\section{Cyclone 2A, 19th May 1999}

In this area, rainfalls and cyclones are common phenomena, responsible for causing damage to the Tidal Link and infrastructures. Before Cyclone 2A, the creeks were connected to the sea $50 \mathrm{~m}$ away from the main city of Badin [17].

\section{RESULTS AND DISCUSSION}

There is a $700 \%$ increase in original Dhands area from 6058 to 41220 acres from 1954 to 1977 due to the operation of Kotri Barrage surface scheme. This has positive impact on Dhands ecology because the drainage effluents are of marginal saline. But the rapid increase in the Dhands area of about $40 \%$ within 2 years after the functioning of the Tidal Link with saline effluents from LBOD and sea intruded water have been changing the ecology of the area.

TABLE I. DHANDS AREA BEFORE TIDAL LINK CONSTRUCTION

\begin{tabular}{|c|c|c|c|c|}
\hline \multirow{2}{*}{ Dhand name } & \multicolumn{3}{|c|}{ Area acres } & \multirow{2}{*}{$\begin{array}{c}\text { Extended area } \\
\text { acres (1997) }\end{array}$} \\
\cline { 2 - 4 } & $\mathbf{1 9 5 4}$ & $\mathbf{1 9 7 7}$ & $\mathbf{1 9 9 1}$ & \multirow{2}{*}{} \\
\hline Cholri & 300 & 5715 & 5560 & \multirow{2}{*}{60,000} \\
\hline Mehro & 620 & 9575 & 9730 & \\
\hline Sanhro & 975 & 16525 & 15908 & \\
\hline Bakradi & 234 & 620 & In Mehro & \multirow{2}{*}{6} \\
\hline Bakar & 1575 & 600 & In Pateji & \\
\hline Pateji & 2354 & 5714 & 6332 & \\
\hline Mandhar & Not exist & 2471 & 4300 & \multirow{2}{*}{60,000} \\
\hline Narahi & Not exist & Dry & Dry & \\
\hline & 6058 & 41220 & 41800 & \multirow{2}{*}{6} \\
\hline
\end{tabular}

\section{A. Sources of Dhands Water Supply}

The sources of water supply of the area are mainly from the tail end channels of Fuleli and Pinyari canal of Kotri Barrage. The area is also supplemented by outfall drains. Kadhan-Pateji, Karo Gunghro and Fulleli Guni discharge into the Dhands area. These drains carry effluents from agricultural lands and storm water during monsoon rains from a total catchment area of more than 2000 sq. miles. Karo-Gunghro outfall drain and Ahmed Rajo branch drain discharge into Sanhro Dhand. FuleliGunni outfall drain discharges into Mehro Dhand. Some sub drains and branch drains of Kadhan-Pateji outfall system discharge via KPOD into the Pateji Dhand (Table II).

TABLE II. DISCHARGES OF KOTRI SURFACE DRAINS IN TIDAL AREA

\begin{tabular}{|c|c|c|}
\hline Drain name & Out fall & Discharge (cusecs) \\
\hline Fulleli Guni Outfalls Drain & Mehro Dhand & 2550 \\
\hline Ahmed Rajo Branch Drain & Mehro Dhand & 80 \\
\hline Karo Gunghro Outfalls Drain & Sanhro Dhand & 1768 \\
\hline KPOD & Tidal Link & 3626 \\
\hline
\end{tabular}




\section{B. Impact of Tidal Link on the Dhand Complex}

In 1995, the Tidal Link was built so that it could withdraw 3 million tons of salt and 0.7 million acre feet of sewage into the sea per year. Issues were brought up concerning the operation of the Tidal Link Drain such as saline water flow rates, water movements and their influence upon the Dhands and coastal wetlands. In order to sustain the area ecology, a long (1800ft) weir was constructed on the Norther Bank of Tidal Link and the south limb of Cholri Dhand. The drain of the Tidal Link does not flow through any agricultural lands. The Cholri weir contributes in maintaining the water balance and quality in Dhands. The water samples were collected from different areas (Figures 1-4) which were affected by the high tide of Sea (before the construction of the Tidal Link) and were sent to the Sindh University for analysis in 1997. The $\mathrm{pH}$ values of all samples have been found within permissible limits except the sample from Sanhro. The electric conductivity was higher at Cholri, Fuleli Tidal-129RD. The other samples were within permissible limits. The measured chloride content was in the range of 1000 to $40000 \mathrm{ppm}$, and the salinity was relatively low in most of the samples.

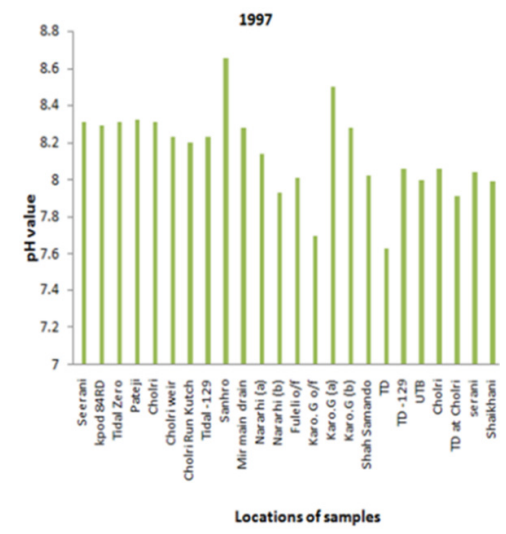

Fig. 1. $\mathrm{pH}$ values before the construction of the Tidal Link

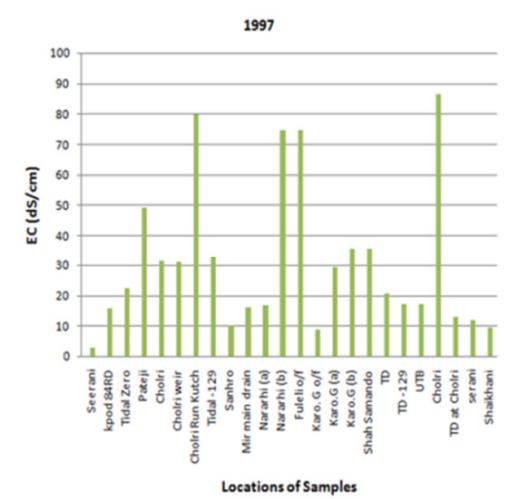

Fig. 2. Electric conductivity before the construction of the Tidal Link

\section{Cyclone $2 A$ and Tidal Link Damages}

The monsoons dominate the coastal zone of Indus Delta from July to September. Most of the damages to infrastructures are caused by cyclones and heavy rainfalls in this area. The cyclone $2 \mathrm{~A}$ damaged the Tidal Link severely. This calamity left the banks of 56 locations with partial breaches. The system could not sustain the storm water due to its failure. The sweet to saline water Dhands like Mehro, Kadan - Pateji, Sanhro and Cholri were turned saline due to seawater intrusion.

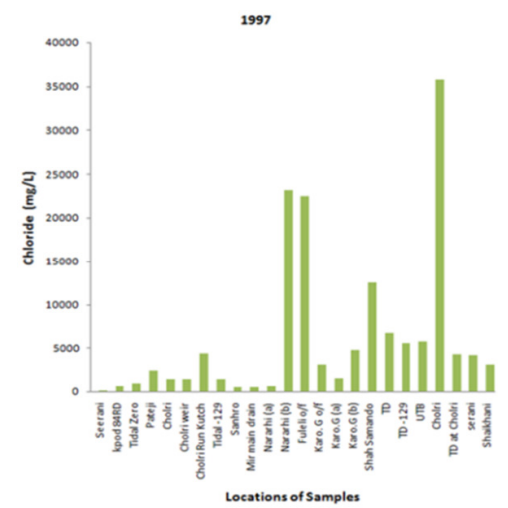

Fig. 3. Cloride values before the construction of the Tidal Link

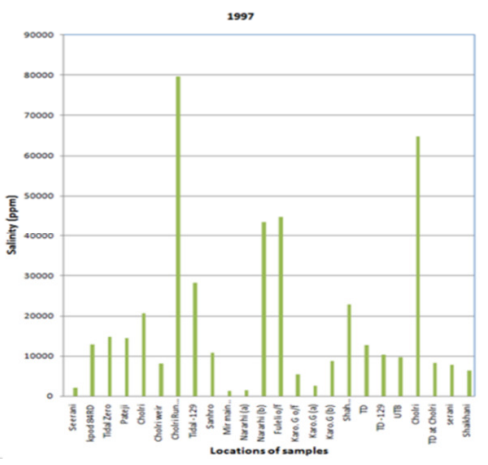

Fig. 4. Salinity values before the construction of the Tidal Link

Before cyclone $2 \mathrm{~A}$ the creeks were connected to the sea water $50 \mathrm{~km}$ away from the main Badin city. The sea water approached many villages at a distance of $35 \mathrm{~km}$ from the main city. Water samples were collected in 2001 from different locations/areas (Figures 5-8) affected by high sea tides before the construction of the Tidal Link and were sent to Sindh University for analysis. The results showed that $\mathrm{pH}$ values of all samples were within permissible limits except the sample from Sanhro. The electric conductivity was higher in the samples from Cholri, Fuleli Tidal-129RD, while the other samples were within permissible limits. The measured chloride content was in the range of 2000 to $16000 \mathrm{mg} / \mathrm{L}$. Salinity refers to the total amount of soluble salts in the water. It is expressed in $\mathrm{dS} / \mathrm{m}$ at $25^{\circ} \mathrm{C}$. Excess soluble salts present in water can change its chemical and physical characteristics. Salinity has been used here as a main indicator for sea water intrusion. The salinity recorded during 2001 shows that Cholri and Pateji dhands were generally as saline as sea water (34000ppm), and that Sanhro and Mehro Dhands were of low salinity (6000ppm) although still well above the salinity of canal water (450ppm). KPOD water had also low salinity (5000ppm) in winter. There is no dilution source for the dhands and adjoining agricultural fields resulting to salt accumulation on the Dhands bed, intrusion on land and spreading on the area through winds. 


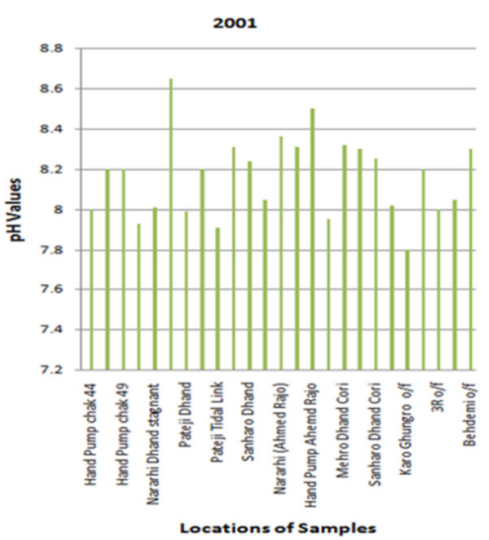

Fig. 5. $\mathrm{pH}$ values after the construction of the Tidal Link

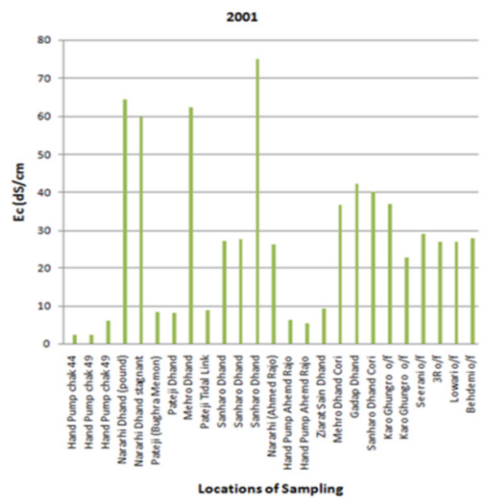

Fig. 6. Electric conductivity after the construction of the Tidal Link

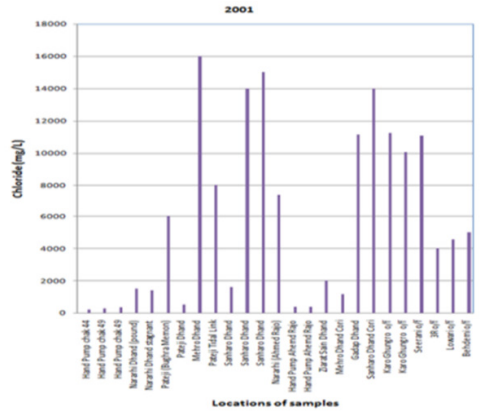

Fig. 7. Cloride values after the construction of the Tidal Link

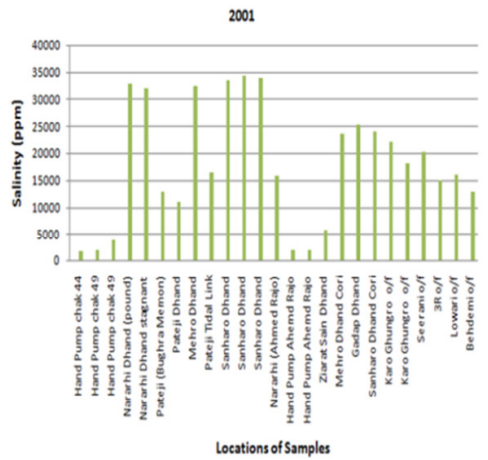

Fig. 8. Salinity values after the construction of the Tidal Link

\section{Seawater Intrusion Tidal Link}

Probably, the main cause of the excess amount of salinity in the tidal link drain is the water exchange between Dhands and the high salinity adjoining creeks. The seawater from Shah Samando Creek has now extended up to RD-55 and beyond. According to the visible topographic changes, the outfall of the tidal link has shifted from RD-155 to an area between RD-93 and RD-125. The water salinity in Tidal Link Drain at various RDs ranged from 30 to $45 \mathrm{ppt}$, the water salinity at RD-93 varied between 30 and $44 \mathrm{ppt}$, but mostly remained between 30 and 35ppt. Lower water salinity indicates the influence of KPOD water in the tidal link drain. No brackish water/fresh water was observed to enter Dhands or the tidal link drain.

\section{E. Seawater Intrusion in Dhands}

The area between the high tidal zone and the agricultural lands contains a few but huge Dhands. The water in these Dhands varies from sweat to saline. High amount of salinity in the Dhands is probably the result of seawater mixing with the Tidal Link and the decreased flows in a few of the Kotri drains (Fuleli and Karo). The flow from Kotri drains consequently ends up in the Tidal Link via Narri Sanhro and Mehro Dhands. Evaporation may be an effective factor for balancing the water level in Dhands. The polluted streams from sugar factories and others may pose a serious threat to them. Figures 9-13 show the values of surface water salinity per year. Water quality has been improved by the recent rainfall flood in 2011. Due to the inter-connection of sea water with Cholri weir, the Narri and associated dhands aren't suitable for accumulating fresh or rainfall water.

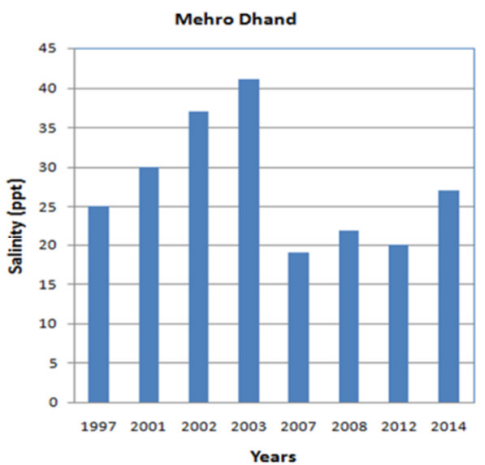

Fig. 9. Salinity of Mehro Dhand

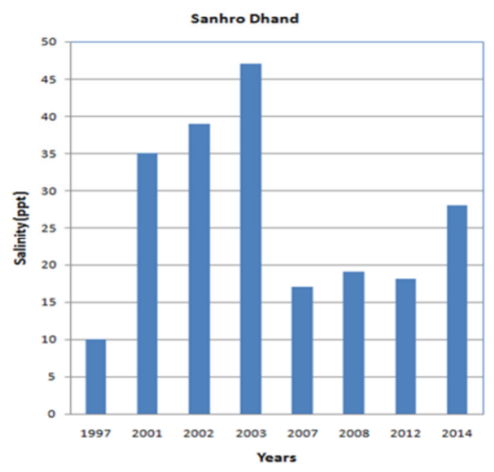

Fig. 10. Salinity of Sahro Dhand 


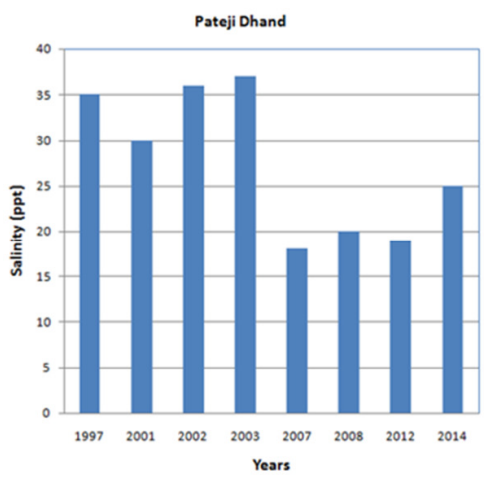

Fig. 11. Salinity of Pateji Dhand

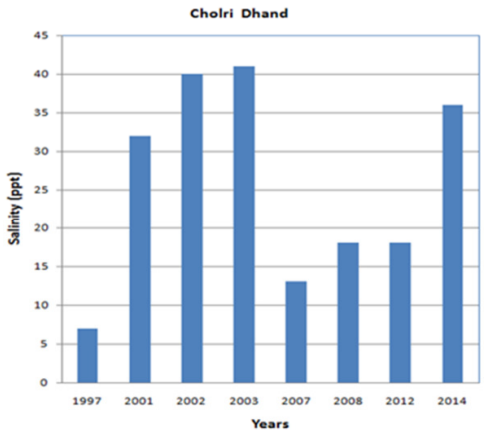

Fig. 12. Salinity of Cholri Dhand

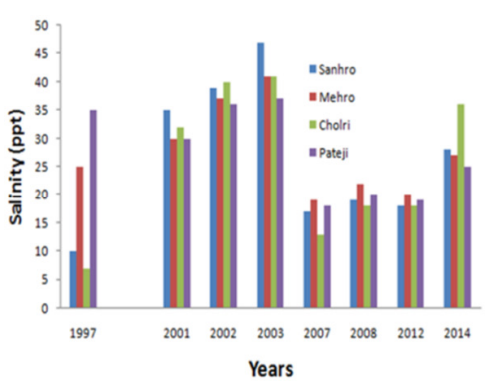

Fig. 13. Salinity of Sahro, Mehro, Cholri and Pateji Dhands

\section{F. Satellite Images of the Dhand Area}

The total area covered by the Dhands (Cholri, Pateji, Sanhro, and Mehro) is about 153 sq. miles. These dhands are interconnected naturally via open narrow channels. Various species of migrating birds from Siberia to North Pole, aquatic life of fish and plants rely on these Dhands for their survival.

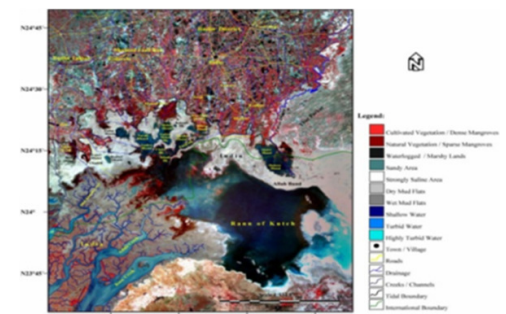

Fig. 14. Satellite image of the Tidal Link area, 21 Oct. 1989

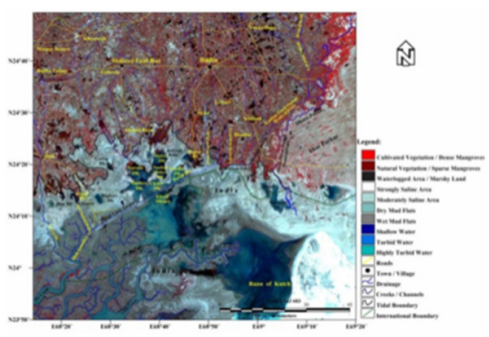

Fig. 15. Satellite image of the Tidal Link area, 3 Feb. 1999

Compared to the 1989 image (Figure 14) of the Tidal Link, the natural vegetation/swamps have vanished in 1999 (Figure 15). When compared to 1999 , a massive water body appears to have shrunk in the southern part of Kadhan, Cholri and Pateji Dhands. Tidal Link Drain appears to have stopped water inflow from irrigation canals draining to Cholri and Patrii to Kadhan and thus converted them to wet mud flats.

\section{G. Environmental and Socioeconomic Impact}

Dhand water attracts thousands of migratory birds from Siberia and Europe from November until the end of March. Dhands serve as feeding grounds, only few of the migratory birds species breed there. The Dhands are rich in aquatic life, they produce large numbers of shrimps and fish, which depend on fresh and sea water during their life cycle. Crops cultivated in the years 1993 to 1998 in the affected area in Rabi (November to May) are: wheat, barely, vegetables, mustard seed, sunflower, hurbo and maize fodder. In Kharif (May to October) are: maize fodder, rice, sugar cane and vegetables. Fish farming is active and growing in this area, with the majority of the workforce belonging to the fisher community. The main stakeholders of the area are small landowners, harees (tenants) and laborers. They are involved in agriculture, small business, livestock, fishing, and various manual labor occupations. Information collected shows that the numbers of small and medium landowners are the majority. The majority of farmers holds lands below 12.5 acres.

\section{CONCLUSIONS}

The Dhands are an environmental concern, they possess estuary ecology and maintain a biodiversity of flora and fauna. The concept of the Cholri Weir was to maintain $5 \mathrm{ft}$ water depth in the Dhands and give way overflow water to the Tidal Link, in order to maintain the ecology of the area. The effect of the natural disaster of the 1999 Cyclone, high tides during the 2000 quake, the 26 May 2001 storm and the 2003, 2006 and 2011 heavy storms further damaged Tidal Link. They have completely shattered the system from Shah Samando creek to Seerani drain. The satellite images show the completely wash away picture of the Tidal Link. There is a free way of sea flooding during high tides and rough weather particularly in monsoon season from Shah Samando creek. These conditions along with drought triggered seawater intrusion in the area severely demaged the area's ecology. Agricultural fields, fresh water reserves and fishing activities have been reduced. Dhand water attraction of migratory birds declined. Inhabitants have to travel far away from their homes in search of basic commodities such as food, water, firewood, fodder, etc. something that directly impacts human life in this area. Wild 
life pattern has changed, the seasonal migrating has not been seen in this area since long, particularly after the failure of the Tidal Link. Sweet water fish have been replaced by saline water species whose majority is carnivore, their colonies are continuously increasing and eventually they will lead the remaining native species to extinction. Generally, the ground water is saline and the residents are depended on the occasionally available canal water or are forced to purchase water from venders. The contaminated water causes various diseases like diarrhea, jaundice, abdominal and skin diseases, which are common in the area. Concluding, the failure of the Tidal Link had a serious impact in the life of common people.

\section{ACKNOWLEDGEMENT}

The authors are thankful to the Sindh Irrigation and Drainage Authority and Sindh Barrages Improvement Project for providing the facilities to conduct this research work.

\section{REFERENCES}

[1] M. E. Habib, Environmental Study Of Seawater Intrusion Around Tidal Link, MSc Thesis, Mehran University of Engineering and Technology, 2013

[2] World Bank Left Bank Outfall Drain Project Talking Pakistan's Waterlogging and Salinity Problems, 1997

[3] S. H. N. Rizvi, J. Baquer, I. Raza, "Disposal of Saline Surface Drain to Inter-tidal Delta, Arabian Sea using Gravity Gradient", Canadian 1999 Coastal Conference, Victoria, Canada, May 19-22, 1999

[4] A. L. Qureshi, S. N. Chandio, S. M. Kori, "Performance Evaluation of Surface Drains in LBOD Project Area: a case study of Spinal Drain", 1st National Seminar on Drainage in Pakistan, Jamshoro, Pakistan, August $16-18,2000$

[5] National Institute of Oceanography, Hydraulic Monitoring of the Tidal Link Drain, Quarterly Progress Report (April - June '99), 1999

[6] R. E. Heimlich, K. D. Wiebe, R. Claassen, D. Gadsby, R. M. House, Wetlands and Agriculture: Private Interests and Public Benefits. Agricultural Economic Report No. 765, Resource Economics Division, Economic Research Service, U.S. Department of Agriculture, 1998

[7] W. J. Mitsch, J. G. Gosselink, Wetlands, Van Nostrand Reinhold, 1993

[8] P. F. Scodari, Wetlands Protection: The Role of Economics, Environmental Law Institute, 1990

[9] United Nations Environmental Programme (UNEP), The Status of the Nigerian Coastal Zones, 2007

[10] G. Asibor, "Wetlands: values, uses and challenges", Paper presented to the Nigerian Environmental Society at the Petroleum Training Institute, Effurun, Nigeria, November 21, 2009

[11] N. O. Uluocha, I. C. Okeke, "Implications of wetlands degradation for water resources management: Lessons from Nigeria”, Geojournal, Vol. 16, pp. 151-154, 2004

[12] R. Akpofure, Environmental Sciences: An Introduction, Kraft Books, 2009

[13] J. R. Schubel, "Estuarine Circulation and Sedimentation: An overview", in: Marine Geology and Oceanography of Arabian Sea and Coastal Pakistan, pp. 113-136, Von Nostrand Reinhold Company, 1984

[14] National Institute of Oceanography, Hydraulic Monitoring of the Tidal Link Drain, Quarterly Progress Report (October - December 2000). National Institute of Oceanography, 2000

[15] National Institute of Oceanography, Hydraulic Monitoring of the Tidal Link Drain, Quarterly Progress Report (October - December 2001). National Institute of Oceanography, 2001

[16] WAPDA, Physical Monitoring of LBOD Stage-1 Project. Revised Work Plan and Cost Estimates 1995/96 to December 1997, Directorate of SCARPS Monitoring (South), 1995
[17] M. E. Leghari, Developing Sustainable Management Plan for Water Supply and Sanitation in Coastal Area of Badin, MSc Thesis, Mehran University of Engineering and Technology, 2013 